\title{
A method of determining the maximum performance torque- speed characteristic for an induction motor drive over its entire speed range
}

Kulik, E., Xuan Trung Tran, Anuchin. A. and Vagapov. Y.

This is a paper presented at the $58^{\text {th }}$ Int. Sci. Conf. on Power and Electrical Engineering of Riga Technical University, Riga, Latvia, 12-13 October 2017.

Copyright of the author(s). Reproduced here with their permission and the permission of the conference organisers.

Recommended citation:

Anuchin. A., Shpak, D., Zharkov, A. Ostrirov, V., and Vagapov. Y. (2017), 'A method of determining the maximum performance torque-speed characteristic for an induction motor drive over its entire speed range'. In: Proc. 58th Int. Sci. Conf. on Power and Electrical Engineering of Riga Technical University, Riga, Latvia, 12-13 October 2017, pp. 1-5, DOI: 10.1109/RTUCON.2017.8124815.

http://ieeexplore.ieee.org/document/8124815/ 


\section{A Method of Determining the Maximum Performance Torque-speed Characteristic for an Induction Motor Drive over its Entire Speed Range}

\author{
Alecksey Anuchin, Dmitry Shpak, Alexandr Zharkov, \\ Vadim Ostrirov \\ Department of Electric Drives \\ Moscow Power Engineering Institute \\ Moscow, Russia \\ anuchin.alecksey@gmail.com
}

\author{
Yuriy Vagapov \\ School of Applied Science, Computing and Engineering \\ Glyndwr University \\ Wrexham, United Kingdom \\ y.vagapov@glyndwr.ac.uk
}

\begin{abstract}
This paper discusses a simple and efficient method of determining the maximum performance torque-speed characteristic for an induction motor drive. The proposed method considers the voltage and current constraints of the inverter supply for the drive. The mathematical description of the motor in DQ reference frames was adapted to build a model applicable for numeric calculation. It has been shown that the torque-speed characteristic has 3 operating speed regions. The optimal relationship between the magnetisation and $q$-axis currents is derived for the third speed region. The model performs tracking of the magnetisation current in order to keep the output voltage and current under the limits of the inverter. In addition, the proposed model provides a method of calculation for the output power, the apparent power, the power factor and the efficiency vs speed. The proposed method is applicable for the analysis of the induction motor drive operating over its entire speed range.
\end{abstract}

Keywords-induction motors; traction motors; inverters; variable speed drives; torque vs speed.

\section{INTRODUCTION}

For many decades the induction motor remained the most popular electrical machine for various industrial applications including traction drives for electrified transportation. The motor requirements for traction applications are very demanding in terms of power density, efficiency and range of speed control [1]. The traction motors for powertrain propulsion usually operate in the constant power or the field weakening mode, excluding the low speed region where constant torque mode is applied. The induction motor control strategies which are implemented to provide efficient traction performance are usually based on field-oriented or direct torque control algorithms in which the maximum performance torque-speed characteristic is an essential component of the control structure [2-5].

The torque-speed characteristic of an induction motor for a traction application can be divided onto three regions in terms of performance analysis. The first region of the characteristic is related to the low speed range where the motor is operating in

The research was performed with the support of the Russian Science Foundation grant (Project № 16-19-10618). the constant torque mode. The drive develops constant torque on its shaft due to the motor operation under the rated flux and rated current. The increase of the shaft speed rises the motor back-EMF until it reaches the maximum permissible voltage of the inverter supplying the drive. In the second region of the torque-speed characteristic the motor is operating under a constant power mode in which the flux is reduced. Under this mode the flux linkage reference is usually generated by the voltage controller keeping the output voltage of the inverter close to the maximum value [6-8]. A further speed increase brings the motor operation into the third region of the characteristic where the leakage inductance has grown to make the reactive component in the stator voltage equal to the active component. From this speed both the field and torque currents should be reduced.

An induction machine has a sophisticated mathematical description and the analytical representation of the second and third regions of the maximum performance torque-speed characteristic has not yet been derived. This characteristic can be evaluated using a model of the control system and the motor [9]. However, the evaluation result only gives a curve which is allocated below the maximum performance limits and depends on the design of the control strategy.

This paper considers an effective numerical method of determining the maximum performance torque-speed characteristic of an induction motor including some extra data such as power factor, efficiency, mechanical and apparent power. This method can be used to define the maximum performance conditions of the drive and to check the limitations of the control strategy operation.

\section{MATHEMATICAL DESCRIPTION OF THE DRIVE OVER ITS ENTIRE SPEED RANGE}

\section{A. Induction Machine Model}

In terms of modelling an induction motor is a non-linear object having variable parameters and cross-couplings. When the motor is operating under field-oriented control it is assumed that most of the motor parameters are constant due to the 
limitation of the motor slip and magnetisation current. Actually, if the motor slip value is insignificantly varying then the rotor resistance remains approximately constant. The limitation of the magnetisation current by the rated value brings the motor operating point in the saturation knee area of the iron magnetising curve. Any further field weakening moves the machine operating point into the linear region of the magnetising curve.

DQ reference frames are synchronised with the rotor flux linkage to represent the main equations of the machine as shown below. The set of equations consists of the stator voltage balance equations for the steady state (1), the torque equation as a function of currents (2) and the torque equation as a function of the slip (3) [10].

$$
\left.\begin{array}{c}
v_{s d}=i_{s d} R_{s}-L_{s} \sigma i_{s q} \omega_{0} \\
v_{s q}=i_{s q} R_{s}+L_{s} i_{s d} \omega_{0}
\end{array}\right\}
$$

where $v_{s d}$ and $v_{s q}$ are $d$ - and $q$-axis voltages respectively, $i_{s d}$ and $i_{s q}$ are $d$ - and $q$-axis currents respectively, $R_{s}$ and $R_{r}$ are the stator and rotor resistance respectively, $L_{s}$ is the stator inductance, $L_{m}$ is the mutual inductance, $\sigma=1-\frac{L_{m}^{2}}{L_{s} L_{r}}$ is global leakage coefficient, $L_{r}$ is the rotor inductance, $\omega_{0}$ is the idle speed, $\omega$ is the current speed and $T$ is the torque. The maximum value of the voltage is defined as the following:

$$
V_{\max } \geq \sqrt{v_{s d}^{2}+v_{s q}^{2}}
$$

The motor is supplied by an inverter where the current should be limited to:

$$
I_{\max } \geq \sqrt{i_{s d}^{2}+i_{s q}^{2}}
$$

Actually, there may be other limits for the current profile. It may depend on speed or it may be evaluated from a thermal model of the drive. However, if the motor is supplied by an ordinary voltage source inverter then the main limitation parameter is the value of the peak or continuous current of the inverter. The suggested method of determining the characteristic is based on this limitation parameter.

\section{B. Definition of the Speed Regions}

\section{1) First speed region}

The first speed region of the torque-speed characteristic is also called a constant torque region. The magnetisation current of the motor under this mode should be limited at the rated value. A further increase of the magnetisation current is futile due to saturation effect in the machine. As the $d$-axis current is set to its rated value the $q$-axis current can be evaluated from (5) according to the current limit:

$$
i_{s q}=\sqrt{I_{\text {max }}^{2}-i_{s d ~ r a t e d}^{2}}
$$

The motor torque can be evaluated using (2). To evaluate the stator voltages by means of (1), the idle speed should be determined first using (3).

$$
\omega_{0}=\omega+\frac{T R_{r}}{L_{m}^{2} i_{s d}^{2}}
$$

The motor operates in the constant torque region until the output voltage of the inverter is below the maximum value according to (4).

\section{2) Second speed region}

In the second speed region of the characteristic the motor performs a constant power operation. This region starts when the inverter voltage reaches the maximum value and the $q$-axis voltage significantly impacts on the magnitude of the output vector. To keep the voltage level below the maximum value at increased speed, the $d$-axis magnetisation current has to be reduced while $q$-axis current can be increased according to (5).

The $d$-axis back-EMF component grows proportionally to the speed if the $q$-axis current is approximately constant. However, when this component becomes equal to the $d$-axis back-EMF component, a further decrease of the $d$-axis current can not prevent the growth of the output voltage. Therefore, a further speed increase moves the operating point on the torquespeed characteristic into the third region.

\section{3) Third speed region}

In the third speed region, it is assumed that the voltage drop across the stator resistance is negligible. Thus, the balance equations (1) can be simplified as following:

$$
\left.\begin{array}{l}
v_{s d}=-L_{s} \sigma i_{s q} \omega_{0} \\
v_{s q}=L_{s} i_{s d} \omega_{0}
\end{array}\right\}
$$

The optimal operating point corresponds to a condition in which both voltage components are equal. To keep the motor operation at the optimum operating point under a further speed increase both the $d$ - and $q$-axis currents should be decreased simultaneously. In this case, the limitation for the $q$-axis current can be expressed from (8) as following:

$$
i_{s q \max } \leq \frac{i_{s d}}{\sigma}
$$

\section{Model WITH D-AXIS CURRENT TRACKING}

It has been mentioned above that there is no analytical solution to the problem of determining the maximum performance torque-speed characteristic for an induction motor in the second and third speed regions. However, this problem can be solved using a single parameter tracking model suggested in this paper. The model is based on the approach in which the currents of the motor are defined in the first speed region and the relationship between currents is defined for third speed region. The change of the $d$-axis current impacts on the flux in the machine and, therefore, on the back-EMF in the third speed region. 
Thus, the value of the $d$-axis current can be obtained from the output of an integrator (see Fig. 1). Its upper limit is equal to the rated magnetisation current. The $q$-axis current for the first and second regions is evaluated using (6) whereas its value for the third speed region is evaluated using (9). The minimum value is taken in order to proceed with further calculations.

At the next stage, the torque, slip and idle load speed are calculated consecutively using (2) and (7). This gives a sufficient information to evaluate the stator voltage by (1) and compare its magnitude with the voltage limit. The difference between the voltage limit and magnitude of the stator voltage is used to track the correct value for magnetisation current. The proposed model is represented by the steady state equations for the induction motor, therefore, there are no limitations for value of the tracking coefficient $k_{\text {tracking }}$ that ensures operational stability of the model. The model block diagram focused on the $d$-axis current tracking is shown in Fig. 1.

This model can be extended to evaluate the output mechanical power, the apparent power (10), the power factor (11), and the efficiency (12).

$$
\begin{gathered}
S=\frac{3}{2} \sqrt{v_{s d}^{2}+v_{s q}^{2}} \sqrt{i_{s d}^{2}+i_{s q}^{2}} \\
\cos (\varphi)=\frac{v_{s d} i_{s d}+v_{s q} i_{s q}}{\sqrt{v_{s d}^{2}+v_{s q}^{2}} \sqrt{i_{s d}^{2}+i_{s q}^{2}}} \\
\eta=\frac{P_{m e c h}}{\frac{3}{2}\left(v_{s d} i_{s d}+v_{s q} i_{s q}\right)}
\end{gathered}
$$

The block diagram of the extended model applied to obtain the torque, the output power, the apparent power, the power factor and the efficiency vs speed is shown in Fig. 2.

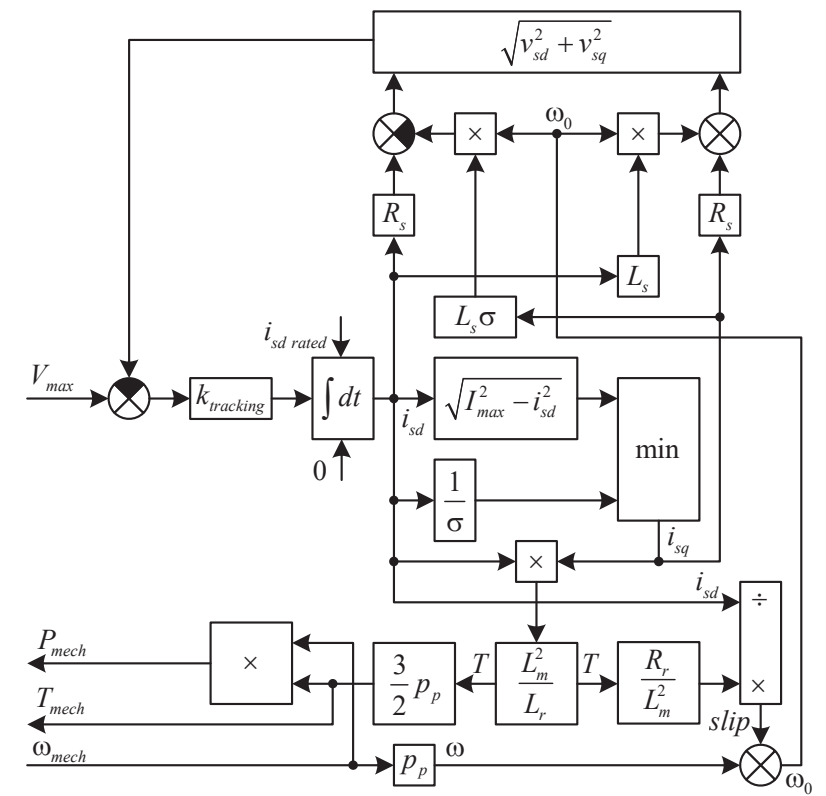

Fig. 1. Block diagram of the tracking model.

\section{Evaluation of the Motor CuRves}

The extended model was implemented using the MATLAB/Simulink software environment. The parameters presented in Table I have been applied for modelling and calculation.

Fig. 3 shows the results of the modelling where three speed regions are clearly visible from the apparent power curve. Other curves demonstrate a relatively smooth connection for two of the three speed regions. For example, the power factor curve has a step in its derivative when moving from the second to the third speed region while the torque and the mechanical power curves have a fracture on the border between the first and the second speed regions.

It should be mentioned that the "constant power region" does not mean constant power on the motor shaft. It means that apparent power holds a constant value over entire second region.

\section{CONCLUSIONS}

This paper proposes a very simple and efficient method for determining the maximum performance torque-speed characteristic of an induction motor drive. This method is applicable for the motor operation over its entire speed range and provides the desired torque-speed characteristic of the drive considering the voltage and current constraints.

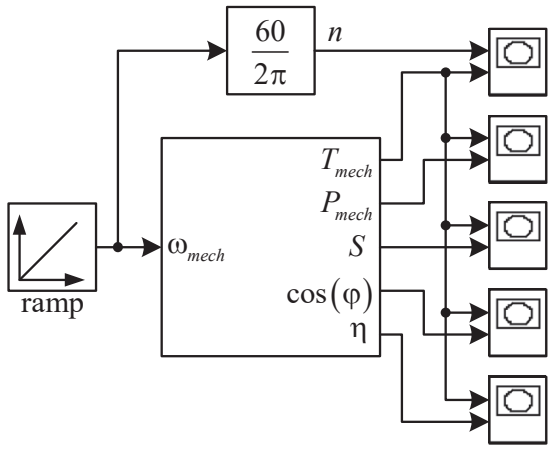

Fig. 2. Block diagram of the extended model for the motor curves evaluation.

TABLE I. PARAMETERS OF THE INDUCTION MOTOR

\begin{tabular}{|l|c|c|}
\hline \multicolumn{1}{|c|}{ Parameter } & Value & Units \\
\hline Mutual inductance & 0.003901 & $\mathrm{H}$ \\
\hline Stator leakage inductance & 0.000102 & $\mathrm{H}$ \\
\hline Rotor leakage inductance & 0.000156 & $\mathrm{H}$ \\
\hline Rotor resistance & 0.013 & $\Omega$ \\
\hline Stator resistance & 0.013 & $\Omega$ \\
\hline Pole pairs & 2 & - \\
\hline Maximum stator current & 367 & Apeak \\
\hline Magnetization current & 119 & Apeak \\
\hline Maximum phase voltage & 312 & Vpeak \\
\hline
\end{tabular}



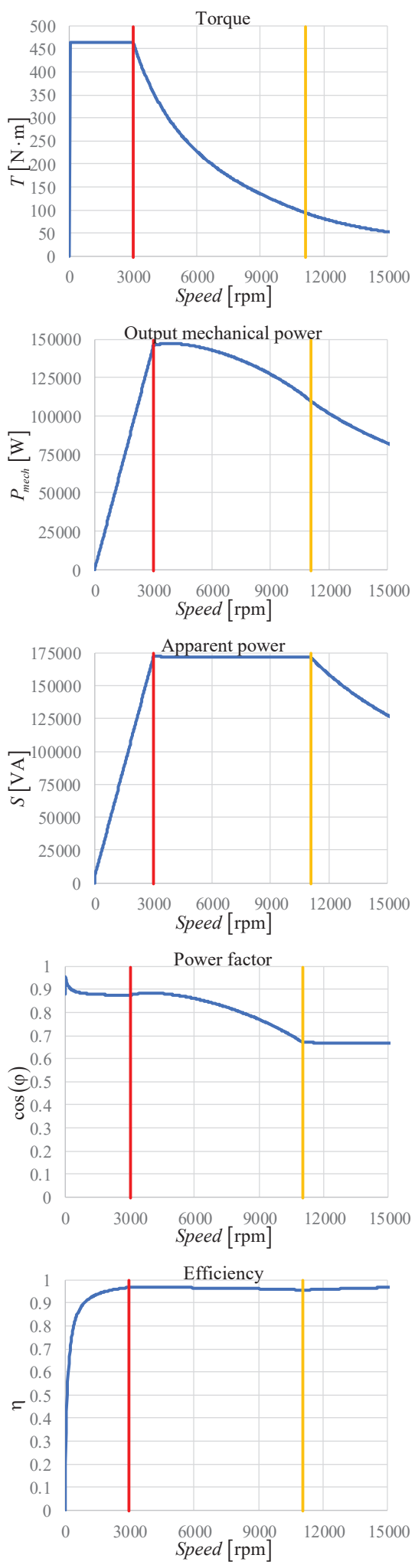

Fig. 3. Torque, output mechanical power, apparent power, power factor and efficiency of the motor vs speed. Red line separates first and second speed regions, orange line separates second and third speed regions.
In addition, this method provides an evaluation of the output power on the motor shaft, the apparent power, the motor efficiency and the power factor vs speed. This method is considered to be a useful tool for engineers involved in the design of induction traction drives including electrical machines, power converters and control system.

\section{REFERENCES}

[1] B. Bilgin, and A. Emadi, "Electric motors in electrified transportation: A step toward achieving a sustainable and highly efficient transportation system," IEEE Power Electronics Magazine, vol. 1, no. 2, pp. 10-17, June 2014.

[2] A.M. El-Refaie, "Motors/generators for traction/propulsion applications: A review," IEEE Vehicular Technology Magazine, vol. 8, no. 1, pp. 9099, March 2013.

[3] M. Ehsani, Y. Gao, and S. Gay, "Characterization of electric motor drives for traction applications," in Proc. IEEE 29th Ann. Conf. Industrial Electronics Society IECON'03, 2-6 Nov. 2003, Roanoke, VA, USA, pp. 891-896.

[4] Bin Gu, and Jih-Sheng Lai, "Control of induction machine with extended range of maximum torque capability for traction drives," in Proc. IEEE Energy Conversion Congress and Exposition ECCE, 17-22 Sept. 2011, Phoenix, AZ, USA, pp. 3590-3595.

[5] M. Zeraoulia, M.E.H. Benbouzid, and D. Diallo, "Electric motor drive selection issues for HEV propulsion systems: A comparative study," IEEE Trans. on Vehicular Technology, vol. 55, no. 6, pp. 1756-1764, Nov. 2006.

[6] $\mathrm{Hu} \mathrm{Hu}$, Yong Dong Li, and Yi Zeng, "Direct torque control of induction motor for railway traction in whole speed range," in Proc. IEEE 28th Ann. Conf. Industrial Electronics Society IECON'02, 5-8 Nov. 2002, Sevilla, Spain, pp. 2161-2166.

[7] Wei Wang, Qingnian Wang, Yuanbin Yu, Xiaohua Zeng, and Naiwei Zou, "Study on the operation region of induction traction motor for electric vehicle," in Proc. Int. Conf. Measuring Technology and Mechatronics Automation ICMTMA'09, 11-12 April 2009, Zhangjiajie, China, pp. 699-703.

[8] X.D. Xue, K.W.E. Cheng, and N.C. Cheung, "Selection of electric motor drives for electric vehicles," in Proc. Australasian Universities Power Engineering Conference AUPEC 08, 14-17 Dec. 2008, Sydney, Australia, pp. 1-6.

[9] Y. Guan, Z.Q. Zhu, I.A.A. Afinowi, J.C. Mipo, and P. Farah, "Difference in maximum torque-speed characteristics of induction machine between motor and generator operation modes for electric vehicle application," Electric Power Systems Research, vol. 136, pp. 406-414, July 2016.

[10] S.-K. Sul, Control of Electric Machine Drive Systems, Wiley, 2011, p. 399.

Alecksey Anuchin received the B.Sc., M.Sc. and Ph.D. degrees from Moscow Power Engineering Institute, Moscow, Russia, in 1999, 2001 and 2004 respectively. He is currently Head of the Department of Electric Drives, Moscow Power Engineering Institute. His topics of interest include control systems for power converters and electric drives, design of instructional laboratories workstations and industrial networks. Address: Krasnokazarmennaya 14, Moscow, 111250, Russia. Email: anuchin.alecksey@gmail.com

Dmitry Shpak received the B.S. and M.Sc. degrees from Moscow Power Engineering Institute, Moscow, Russia, in 2013 and 2015 respectively. He is currently Ph.D. student of the Department of Electric Drives, Moscow Power Engineering Institute. His topics of interest include control systems for power converters and electric drives. Address: Krasnokazarmennaya 14, Moscow, 111250, Russia. Email: disona@yandex.ru

Aleksandr Zharkov received the B.S., M.Sc. and Ph.D. degrees from Moscow Power Engineering Institute, Moscow, Russia, in 2001, 2003 and 2008 respectively. He is currently Assistant professor of the Department of Electric Drives, Moscow Power Engineering Institute. His topics of interest include control systems for power converters, digital signal processing and 
electric drives. Address: Krasnokazarmennaya 14, Moscow, 111250, Russia. Email: zarckov@mail.ru

Vadim Ostrirov received Ph.D. degree and Dr. of Tech. Sc. degree (full professorship) from Moscow Power Engineering Institute, Moscow, Russia, in 1980 and 2004 respectively. He is currently professor of the Department of Electric Drives, Moscow Power Engineering Institute. His topics of interest include power electronics circuits for different kinds of semiconductor converters and design of power converters for various applications. Address: Krasnokazarmennaya 14, Moscow, 111250, Russia. Email: OstrirovVN@cycle-p.ru

Yuriy Vagapov received the Dip.Eng. and Ph.D. degrees from Nizhny Novgorod State Technical University, Nizhny Novgorod, Russia, in 1982 and 1995 respectively. He is a Reader in Electrical Engineering at Glyndwr University, Wrexham, Wales, U.K. His academic interests are in the area of electrical engineering specifically power electronics, electrical machines and drives, and electric vehicles. He is a Chartered Engineer and member of The IET. Address: Plas Coch, Mold Road, Wrexham, LL11 2AW, U.K. Email: y.vagapov@glyndwr.ac.uk 